\title{
Mangrove Mapping and Above-Ground Biomass Change Detection using Satellite Images in Coastal Areas of Thai Binh Province, Vietnam
}

\author{
Long Duc Nguyen ${ }^{1}$, Cuong Trong Nguyen ${ }^{2}$, Hoa Sy Le ${ }^{3}$ and Bao Quang Tran ${ }^{2, *}$ \\ 1 Non-Timber Forest Products Research Center, Vietnam Academy of Forest Sciences, 08 Chuong Duong \\ Do, Hoan Kiem, Ha Noi, Vietnam; Tel: +84 97.938.038; E-mail: long.qltntn@gmail.com \\ 2 Faculty of Forest Resources and Environmental Management, Vietnam National University of Forestry, \\ Xuan Mai, Chuong My, Ha Noi, Vietnam \\ 3 Institute of Forest Ecology and Environment, Vietnam National University of Forestry, Xuan Mai, Chuong \\ My, Ha Noi, Vietnam \\ * Correspondence author: baofuv@vnuf.edu.vn; Tell: +84 945.043.274
}

\begin{abstract}
Mangroves are recognized as a highly valuable resource due to their provision of multiple ecosystem services. Therefore, mangrove ecosystems mapping and monitoring is a crucial objective, especially for tropical regions. Thai Binh province is one of the most important mangrove ecosystems in Vietnam. The mangrove ecosystem in this province has faced threats of deforestation from urban development, land reclamation, tourism activities, and natural disasters. Recently, to maintain the fundamental functions of the ecosystems, a large mangrove area was planted in Thai Binh. The aim of this research is to detect the change in the mangrove areas and to create an aboveground biomass map for mangrove forests in Thai Binh province. Landsat and Sentinel-2 satellite images from 1998 to 2018 were analysed using the supervised classification method to detect mangrove area change. Mangrove Aboveground Biomass ( $A G B$ ) was estimated using linear regression between vegetation indices and field $A G B$ survey. The accuracy assessment for the classified images of 1998, 2003 and 2007, 2013 and 2018 are 93\%, $86 \%, 96 \%, 94 \%$ and $91 \%$ respectively with kappa of $0.8881,0.7953,0.9357,0.9114$ and 0.8761 . The mangrove cover in the study area was estimated at 5874.93 ha in 1998 . This figure decreased significantly to 4433.85 ha in 2007, before recovery began to take place in the study area, which was estimated at 6587.88 ha in 2018. In 1998, the average AGB in this study area was 22.57 ton/ha, and in 2018 it was 37.74 ton/ha with a standard error of 12.41 ton/ha and the root mean square error (RMSE) was \pm 12.08 ton/ha.
\end{abstract}

Keywords: Above Ground Biomass; Mangroves; Change Detection; Remote Sensing

\section{Introduction}

Mangroves are important coastal resources that provide valuable ecosystem goods and services (Alongi, 2002). Mangroves play an important role in nature conservation and socioeconomic development of the local communities (Kamal \& Phinn, 2011). Mangroves can help stabilize the local shorelines and alleviate the devastating impacts of nature, such as dissipating incoming wave energy, trapping sediments in their roots, protecting the land, and standing a barrier against wind. They also provide important ecological and social well-being through ecosystem services. Moreover, mangroves are important habitats for fishes, crabs, and shrimps (Giri, Pengra, Zhu, Singh, \& Tieszen, 2007).

In 2000, the mangrove forest area in the world was estimated at $137,760 \mathrm{~km} 2$ in 118 countries and territories (Giri et al., 2011). The decline of mangroves was caused by over-exploitation, tourism, aquaculture cultivation, and urban development (Alongi, 2002). Globally, mangroves have decreased by more than 3.6 million hectares since 1980. The greatest mangrove loss in Asia to date was 1.9 million hectares (FAO, 2007). In the Southeast Asia region, these mangroves have the highest biodiversity in the world (Polidoro et al., 2010). In Vietnam, the area of mangrove forests were about 400,000 hectares in the early 20th century. However that area declined dramatically 
over the next 50 years (Tuan, Yukihiro, Dao, Tho, \& Dao, 2003). In Northern parts of Vietnam, from Mong Cai to Do Son, throughout the periods 1964-1997, mangrove areas decreased by 17,094 ha. In recent years, mangrove forests have been threatened by socio-economic development approaches (Alongi, 2002). Therefore, mapping mangrove distribution and biomass in Vietnam is an essential tool for mangrove conservation and management.

Remote-sensing has a high potential to detect, identify, and monitor mangrove conditions and changes (Green, Clark, Mumby, Edwards, \& Ellis, 1998). The advances in remote sensing technology could provide new data resources for mapping mangrove forests (Heumann, 2011). Thus, studies on the use of remote sensing data are necessary. Allometric equations for above ground biomass estimation are still limited and mainly used for common forest types other than mangroves. The mangrove biomass estimation methods based on vegetation indices have been used to reduce cost and improve estimation accuracy (Anaya, Chuvieco, \& Palacios-Orueta, 2009), (Green et al., 1998), (Hamdan, Aziz, \& Hasmadi, 2014), (Heumann, 2011), (Kumar \& Mutanga, 2017)). Therefore, the objectives of this study are mapping mangrove forest changes, and determining the amount of above-ground biomass (AGB) in mangroves in the Thai Binh coastal area using allometric equations in association with remote sensing data.

\section{Materials and methods}

\subsection{Study area}

The study was conducted in Thai Binh Province coastal area and Xuan Thuy national park (Giao Thuy district - Nam Dinh province), that is part of the Red River Delta of Vietnam (Figure 1). The study only considered 57,100 ha in three districts (Thai Thuy, Tien Hai and Giao Thuy) in Thai Binh and Nam Dinh province located in the eastern of Vietnam. This area has the average annual precipitation from $1,500 \mathrm{~mm}$ to $1,900 \mathrm{~mm}$, the average temperature from $230 \mathrm{C}$ to $24 \mathrm{oC}$. The lowest temperature in the study area can be lower than $50 C$ (Trần et al., 2016). The main mangrove species in the study area were Acrostichum aureum, Acathus ebracteatus, Acathus ilicifolus, Sensuvium portulacastrum, Avicennia marina, Lumnitzera racemose, Derris trifoliata, Excoecaria agallaocha, Aegiceras corniculatum, Bruguiera gymnorrohiz, Kandelia obovate, Rhizophora stylosa, and Sonneratia caseolaris (Cúc, 2013).

\subsection{Satellite data}

Landsat satellite images of the study area were obtained from the United States Geological Survey (USGS). We used Landsat 5 TM, Landsat 7 ETM+ and Landsat $8 \mathrm{OLI}$ with the spatial resolutions of 30 $\mathrm{m}$, and Sentinel 2 with the spatial resolution of $10 \mathrm{~m}$. The acquisition date and part/row of images were showed in Table 1.

The selected satellite images were captured in 1998, 2003, 2007, 2013, and 2018 with no cloud cover the study area to monitor the mangrove area change. Particularly, the satellite image in 2018 was used for mangrove mapping and to estimate aboveground biomass in association with data from ground surveys.

Table 1. Satellite images used in the study

\begin{tabular}{ccccc}
\hline No & Acquisition date & Image & Resolution & Path/row \\
\hline $\mathbf{1}$ & 02/11/1998 & LT05_L1TP_126046_19980929_20161221_01_T1 & $30 \times 30$ & $126 / 46$ \\
$\mathbf{2}$ & 21/10/2003 & LE07_L1TP_126046_20031021_20170123_01_T1 & $30 \times 30$ & $126 / 46$ \\
$\mathbf{3}$ & 02/02/2007 & LE07_L1TP_126046_20070202_20170105_01_T1 & $30 \times 30$ & $126 / 46$ \\
$\mathbf{4}$ & $08 / 10 / 2013$ & LC08_L1TP_126046_20131008_20170429_01_T1 & $30 \times 30$ & $126 / 46$ \\
$\mathbf{5}$ & 07/05/2018 & S2A_MSIL1C_20180705T031541_N0206_R118_T48 & 10×10 & \\
& & QXH_20180705T061521 & \\
\hline
\end{tabular}




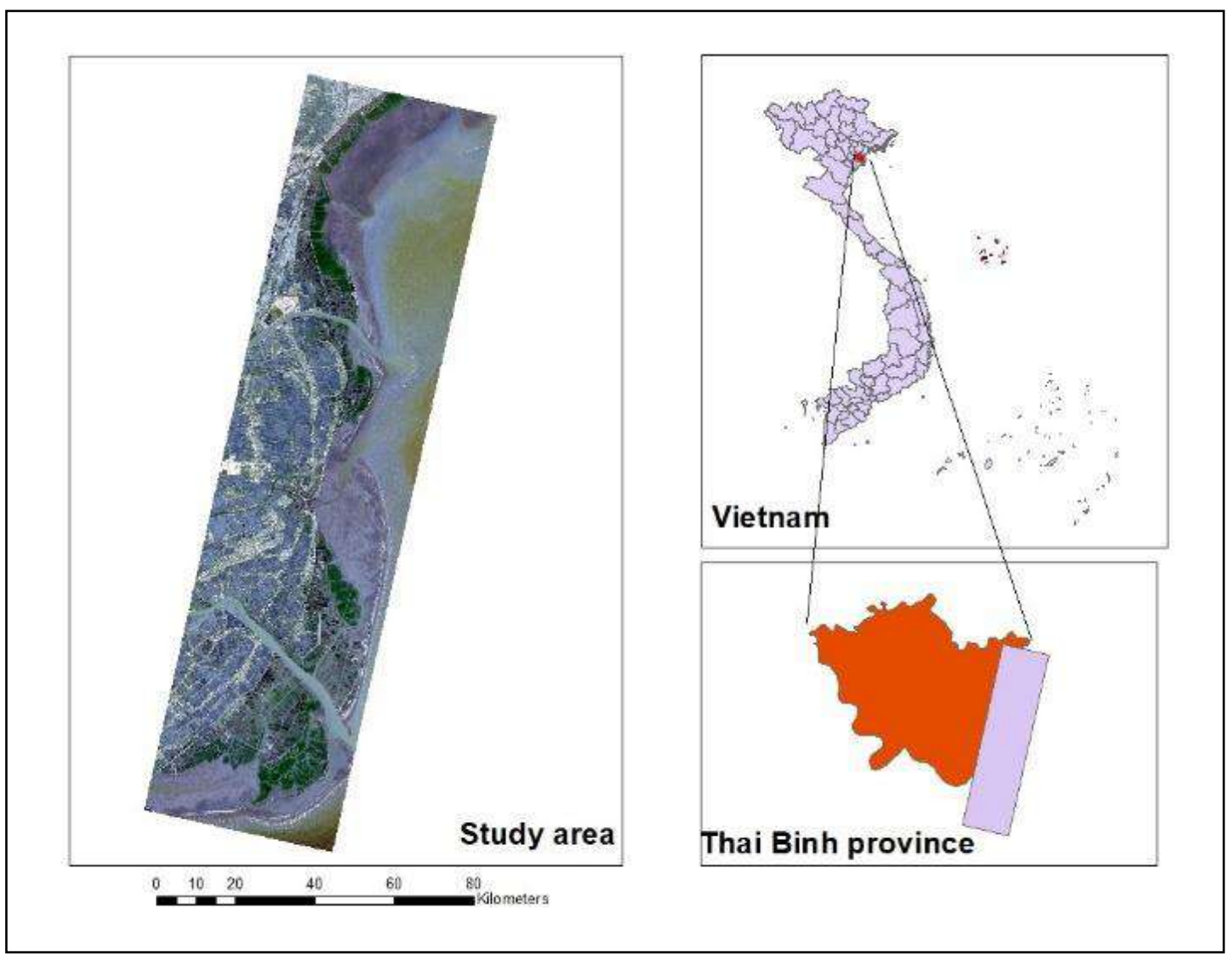

Figure 1. Location map of the study area

\subsection{Field data}

Field data were collected in March 2018 along the coastal line of Thai Binh province. The sample plots were distributed only in easily accessible areas, and the sampling design was based on the simple random sampling method. In total, 37 circle sample plots of 0.1 ha area were investigated and measured during the summer of 2018. Tree inventory and sampling were conducted in circular sample plots of 0.1 ha with a radius of $17.84 \mathrm{~m}$. Field data collection included mangrove species, diameter of breast height (DBH), and diameter at $0.3 \mathrm{~m}\left(\mathrm{D}_{0.3}\right)$. All trees with $\mathrm{DBH}$ or $\mathrm{D}_{0.3} \geq 1 \mathrm{~cm}$ in the sample plot were measured using diameter tape at the height of $30 \mathrm{~cm}$ above the highest prop roots. Universal Transverse Mercator (UTM) Grid Zones 48N coordinate system was used to record the coordinates of the plot.

\subsection{Estimation mangrove biomass}

Aboveground biomass can be measured or estimated both destructively and non-destructively. Estimating biomass using the destructive method is limited to a small area due to its high consumption in terms of time, cost, labor and the destructive impacts on the local natural ecosystem. The non-destructive methods are based on allometric equations and remote sensing. The allometric equations can estimate the biomass of mangrove using some parameters such as diameter at breast height (DBH) and tree height (Kumar \& Mutanga, 2017). Several methods, which confirmed that remote sensing is possible to estimate mangrove biomass, have been already developed and published. Remote sensing is a great data source facilitating field surveys by avoiding 
the destructive method and reducing time and cost for field surveys (Anaya et al., 2009; MuhdEkhzarizal, Mohd-Hasmadi, Hamdan, Mohamad-Roslan, \& Noor-Shaila, 2018; Winarso et al., 2017).

In this study, the total AGB was estimated by species-specific allometric equations (Komiyama, Poungparn, \& Kato, 2005) using the Global Wood Density Database density values of oven-dry wood for all species in the mangrove forest (Amy E. et al., 2016).

The estimation of AGB was based on tree diameter and wood density, which were measured in the field. The equation for AGB can be expressed as follows:

$$
A G B=0.251 \rho \times D^{2.46} \quad \text { (Komiyama et al., 2005) }
$$

Where: $A G B=$ above ground biomass $(\mathrm{kg})$

$\mathrm{p}=$ wood density $\left(\mathrm{g} / \mathrm{cm}^{3}\right)$

$\mathrm{D}=$ Diameter at $0.3 \mathrm{~m}$ with Rhizophoraceae species and $\mathrm{D}=$ Diameter at breath Height for other species $(\mathrm{cm})$

The AGB of Kandelia candel species are not included in list of species created by Komiyama et al. (2005). Khan et al. (2005) estimated AGB of K. candel following the equation below (Khan, Suwa, \& Hagihara, 2005; Komiyama et al., 2005):

$$
\mathrm{AGB}=0.04117\left(D_{0.1}^{2} \mathrm{H}\right) \quad \text { (Khan et al., 2005) }
$$

Where: $A G B=$ aboveground biomass $(\mathrm{kg})$

$\mathrm{D}_{0.1}=$ Diameter at $0.1 \mathrm{~m}$ of height $(\mathrm{cm})$

$\mathrm{H}=$ the total height tree $(\mathrm{m})$.

\subsubsection{Vegetation index}

Vegetation density has been detected by vegetation indices (VIs) from optical remote sensing images. The vegetation indices have been used to predict the biomass of forest, and normalized difference vegetation index (NDVI) is the most common vegetation index (Li et al., 2007). However using only NDVI can significantly underestimate the biomass of some woody mangroves (Foody et al., 2001). This study used three different vegetation indices to predict mangrove AGB include: Normalized Difference Vegetation Index (NDVI), Soil-Adjusted Vegetation Index (SAVI) and Green Normalized Difference Vegetation Index (GNDVI).

Table 2. Equation for selected vegetation indices

\begin{tabular}{ll}
\hline \multicolumn{1}{c}{ The equation for Vegetation Indices } \\
\hline NDVI $=(($ NIR - RED $) /($ NIR + RED $))$ & (Zaitunah, Ahmad, \& Safitri, 2018). \\
SAVI $=\frac{P_{N I R}-P_{\text {Red }}}{P_{N I R}+P_{\text {Red }}+L}(L+1)$ & (Huete, 1988) \\
GNDVI $=($ NIR - green $) /($ NIR + green) & (Gitelson, Kaufman, \& Merzlyak, 1996)
\end{tabular}

$N D V I=$ normalized difference vegetation indices, $S A V I=$ soil-adjusted vegetation indices, $G N D V I=$ green NDVI; wavelength channels: green, red (R), infrared (IR) and near infrared (NIR)

For AGB estimation, we used backscatter characteristics of mangrove forests in Southeast Asia. A number of researchers (Anderson, Hanson, \& Haas, 1993), (Zheng et al., 2004), (Mutanga, Adam, \& Cho, 2012) published empirical functions to estimate $A G B$, as derived from the relationship between vegetation indices and $A G B$ values measured in field sample plots. 


\subsection{Image processing}

All Landsat and sentinel data were pre-processed to allow inter-comparison between these data, to normalize the data, to correct the atmospheric effects, and reduce noises. The Landsat 7 ETM+ image, which had scan line errors on the image after acquisition due to sensor malfunction was repaired by the gap filling tool in ENVI 4.5 (Abburu \& Golla, 2015). The analyses included atmospheric correction, radiometric correction, map enhancement, band combination, spatial filtering, multispectral data creation, gap-filling analysis and cloud masking was using in ArcGIS 10.2 and SNAP Sentinel toolbox. The images were then geometrically registered to the WGS84 projection system. Radiometric and atmospheric effects were removed from satellite images. This process was performed by the conversion of digital number values in Landsat images into reflectance values.

Image classification can be considered as the process of pattern recognition or identification of the pattern associated with each pixel position in an image in terms of the characteristics of the objects or materials those are presented at the corresponding point on the earth's surface (Syed, Hussin, \& Weir, 2001). In this study, a supervised Maximum Likelihood Classification method was used for the classification. Five major classes were delineated: open mangrove, dense mangrove, water, agriculture area and other classes. The composited bands were represented as false color combination.

This study correlated certain variables from vegetation indices derived from Landsat and Sentinel 2 image with the measured AGB. These vegetation indices were (1) NDVI, (2) soil-adjusted vegetation index (SAVI) and (3) green NDVI (GNDVI). The equations for these vegetation indices are provided in Table 2. All image indices were used for regression analysis.

\subsection{Accuracy assessment and model validation}

Accuracy assessment forms an integral part of the classification process (Regression, 2016). 100 ground points were collected by creating a random point tool in ArcGIS 10.2. Accuracy assessment used The Error Matrix method and the Kappa coefficient of the classification. The main advantage of using Kappa coefficient is the ability to use the value as the basis for determining the statistical significance of any given matrix or the differences among matrixes (Banko, 1998). Kappa coefficients are interpreted using the guidelines outlined by Landis and Koch (1977), where strength of the kappa coefficients is interpreted in the following manner: 0.01-0.20 slight; 0.21-0.40 fair; 0.41-0.60 moderate; 0.61-0.80 substantial; 0.81-1.00 almost perfect (Landis \& Koch, 1977).

A validity check was performed to measure the prediction accuracy. Thus, the validation process is essential before any model can be used. The predicted AGB obtained from the model was correlated with the calculated $A G B$ to observe the coefficient of determination $\left(R^{2}\right)$ of model validation. Furthermore, the Root Mean Square Error (RMSE) was also calculated (Chai \& Draxler, 2014).

\section{Result and discussion}

\subsection{Mangrove classification mapping}

By comparing classified images from two adjacent time points, the area mangroves changed was identified (Figure 2). From 1998s to 2018s, dense mangrove forests in Thai Binh province increased by $1072.85 \mathrm{ha}$ (78.5\%) and open mangrove forests decreased by 359.5 ha $(7.9 \%)$. The change in mangrove area, however, was instable from 1998s to 2007s and from 2007s to 2018s. From the 1998s to 2007s, both open mangrove forest area and dense mangrove forest area decreased by $6.1 \%$ and $11.9 \%$, respectively. Dense mangrove forests lost $162.63 \mathrm{ha}$, although natural forest increase from open mangrove to dense mangrove are quite high in this area (Table 3 ). 
Mangrove forest area changes were insignificant in the context of errors associated with classification and the dynamic nature of mangrove ecosystems. In other words, these changes were well within the error margin. For example, because of the fluctuation of tide, selected areas in flooded areas, barren lands, and water bodies could easily be misclassified from one class to another.

In the period from 2007 to 2018, open mangrove forests slightly decreased by 81.45 ha (1.9\%), but dense mangrove forests significantly increased by 605.03 ha $(102.651 \%)$. This increase was generally expected based on the management, reforestation/afforestation and protection policies of Thai Binh province, including the ban on forest encroachment.

Most of mangrove forests in Thai Binh province are replanted except the natural mangrove in Xuan Thuy National Park (Giao Thuy district). In 1994, the coastal zone in Thai Thuy district was the focus of a project entitled the Thai Binh Environmental Preservation Project, implemented by the Danish Red Cross and the Vietnam Red Cross. More than 1000 ha of mangroves were planted in five coastal communes in Thai Thuy district. Areas with Major Land Use and Land Cover (LULC) change were concentrated in the outer periphery and near the shoreline, caused by anthropogenic and natural forces, respectively (Figure 2). The change between mangrove and non-mangrove is primarily due to the conversion from forest to aquaculture, aggradation; mangrove area increases due to sedimentation, and the results of mangrove rehabilitation programs. A new land was formed in Thai Thuy district that leads to the expansion of mangrove forests (Figure 2).

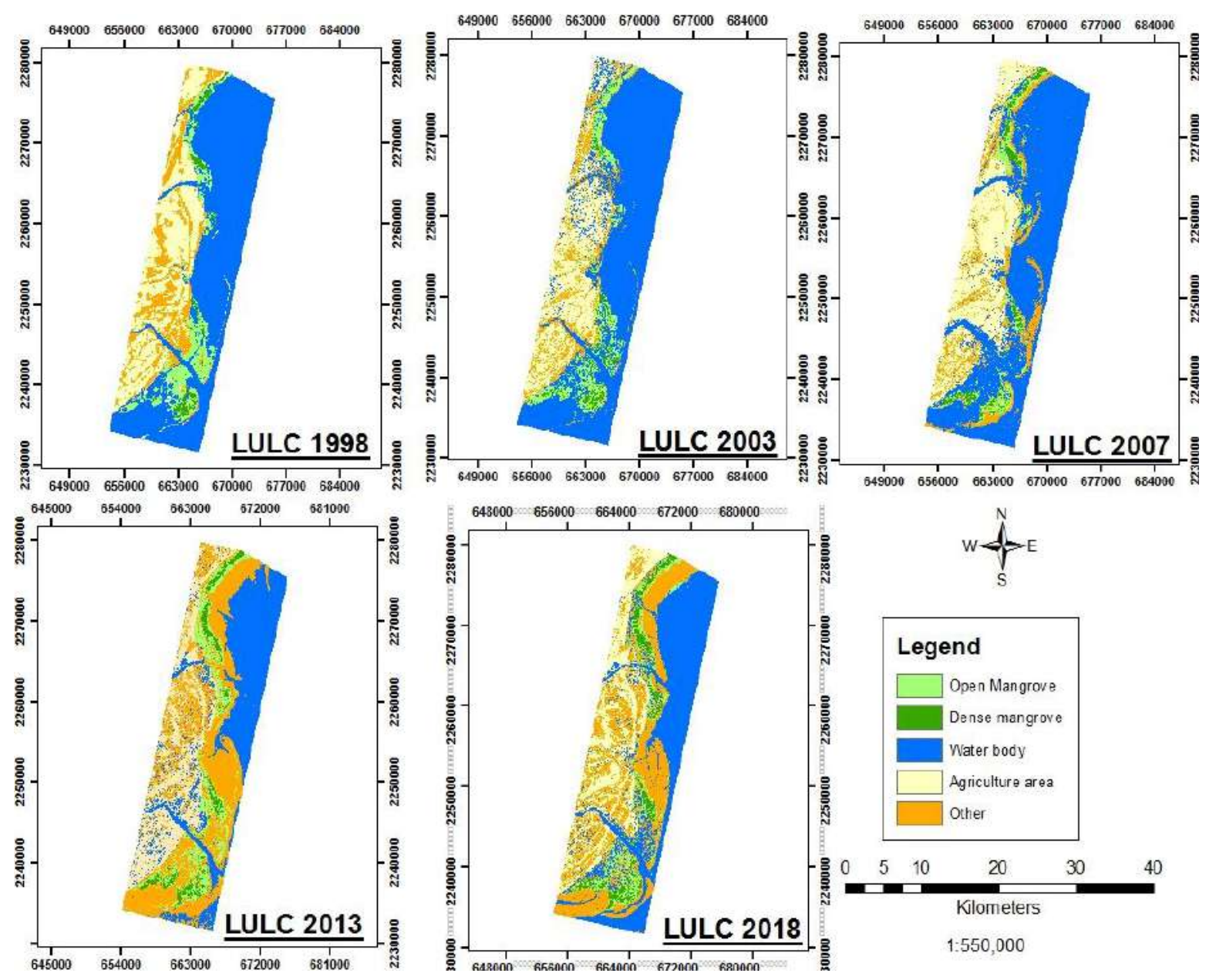

Figure 2. Land Use Land Cover Map in 1998, 2003, 2007, 2013, 2018 
Table 3. The estimates area of LULC for Years 1998, 2003, 2007, 2013, 2018

\begin{tabular}{cccccc}
\hline & $\begin{array}{c}\text { Open mangrove } \\
\text { (ha) }\end{array}$ & $\begin{array}{c}\text { Dense mangrove } \\
\text { (ha) }\end{array}$ & $\begin{array}{c}\text { Water } \\
\text { (ha) }\end{array}$ & $\begin{array}{c}\text { Agriculture area } \\
\text { (ha) }\end{array}$ & $\begin{array}{c}\text { Other } \\
\text { (ha) }\end{array}$ \\
\hline $\mathbf{1 9 9 8}$ & 4508.73 & 1366.20 & 29783.07 & 12119.30 & 7400.52 \\
$\mathbf{2 0 0 3}$ & 4563.45 & 1372.32 & 31008.60 & 11910.60 & 6355.17 \\
$\mathbf{2 0 0 7}$ & 3230.28 & 1203.57 & 28746.09 & 13969.44 & 8060.85 \\
$\mathbf{2 0 1 3}$ & 4511.07 & 1834.02 & 26089.20 & 11636.91 & 13208.85 \\
$\mathbf{2 0 1 8}$ & 4148.83 & 2439.05 & 18913.04 & 7859.42 & 21849.95 \\
\hline
\end{tabular}

\subsection{Accuracy Assessment}

Two confusion matrixes were created to assess the overall accuracy and Kappa coefficient. A random sampling design was adopted in the accuracy assessment. For LULC map, 100 pixels were selected for each year, which were then checked with reference to the Google Earth map and existing land use/cover maps.

Overall accuracy of $93 \%, 96 \%, 86 \%, 94 \%$ and $91 \%$ were achieved for $1998 \mathrm{~s}, 2003 \mathrm{~s}, 2007 \mathrm{~s}, 2013 \mathrm{~s}$ and 2018s with the Kappa coefficient ( $\mathrm{k}$ ) of $0.8881,0.7953,0.9357,0.91$ and 0.8761 , respectively (Table 4).

Table 4. Classified Images accuracy assessment in 1998, 2003, 2007, 2013, 2018

\begin{tabular}{llllll}
\hline Years & $\mathbf{1 9 9 8}$ & $\mathbf{2 0 0 3}$ & $\mathbf{2 0 0 7}$ & $\mathbf{2 0 1 3}$ & $\mathbf{2 0 1 8}$ \\
\hline Overall accuracy (\%) & 93 & 96 & 86 & 94 & 91 \\
Overall Kappa & 0.8881 & 0.7953 & 0.9357 & 0.9114 & 0.8761 \\
\hline
\end{tabular}

\subsection{Mangrove biomass estimating}

According to field AGB observations, an average of 34.7 ton/ha of AGB was estimated, which was ranging from 8.6 ton/ha to 111.3 ton/ha within the sample plots.

The above-ground biomass in the 37 sample plots were estimated by summing the individual components of tree biomass. Then, the biomass derived from the field survey was plotted against above-ground biomass estimated using the data from the satellite data. The linear regression method was used to build the prediction models for AGB by using vegetation indices. The scatterplots generated from the linear regression analysis (Figure 3 ) indicated the relationship between vegetation indices and measured $A G B$ values. The results show that $R^{2}$ value and RMSE in different models of NDVI, SAVI and Green NDVI are not insignificantly different. In these models, SAVI attended the highest $R^{2}$ value (0.685), followed by NDVI model (0.676), and the lowest $R^{2}$ value is GNDVI model. NDVI, SAVI, and GNDVI models have slightly different with RMSE of 12.084, 12.080, and 12.058 respectively.

In investigated sample plots, the AGB in a plot in Xuan Thuy National Park is higher than others, but vegetation index value in the corresponding pixel is the same as in other plots. The difference occurs because vegetation indices cannot be used for mixed-species forests. The sample plots with $A G B$ values higher than others are mix-species mangrove forests, and they have two different canopy layers. We found that the characteristics of mangroves in almost the study area are even aged and a pure species. This type of mangrove commonly has homogenous tree height and one canopy layer. This condition leads to high correlation between vegetation indices and mangrove biomass, since the third parameter of tree height is homogenous. 
Table 5. Summary of simple linear regression models using single independent variable

\begin{tabular}{|c|c|c|c|c|c|c|c|}
\hline No. & $\begin{array}{l}\text { Vegetation } \\
\text { index }\end{array}$ & Model & $\mathbf{R}$ & $\mathbf{R}^{2}$ & Adjusted $\mathrm{R}^{2}$ & $\begin{array}{c}\text { RMSE } \\
\text { (士ton/ha) }\end{array}$ & $\begin{array}{c}\text { Standard } \\
\text { Error }\end{array}$ \\
\hline 1 & NDVI & $\mathrm{Y}=148.31 \mathrm{x}-41.019$ & 0.822 & 0.6762 & 0.667 & 12.084 & 12.41 \\
\hline 2 & SAVI & $Y=98.887 x-41.017$ & 0.828 & 0.6762 & 0.667 & 12.080 & 12.41 \\
\hline 3 & GNDVI & $Y=227.65 x-58.542$ & 0.823 & 0.6774 & 0.668 & 12.058 & 12.38 \\
\hline
\end{tabular}

When understory trees were covered by the canopy layer (Figure 4), the resulting uncounted biomass would lead to an underestimation of total AGB. In this study, most of surveyed sample plots were even-aged pure species, and only one plot was uneven-aged and mixed species. If the mangrove forests in consideration are uneven-aged or mixed species, the accuracy of this method will be low.
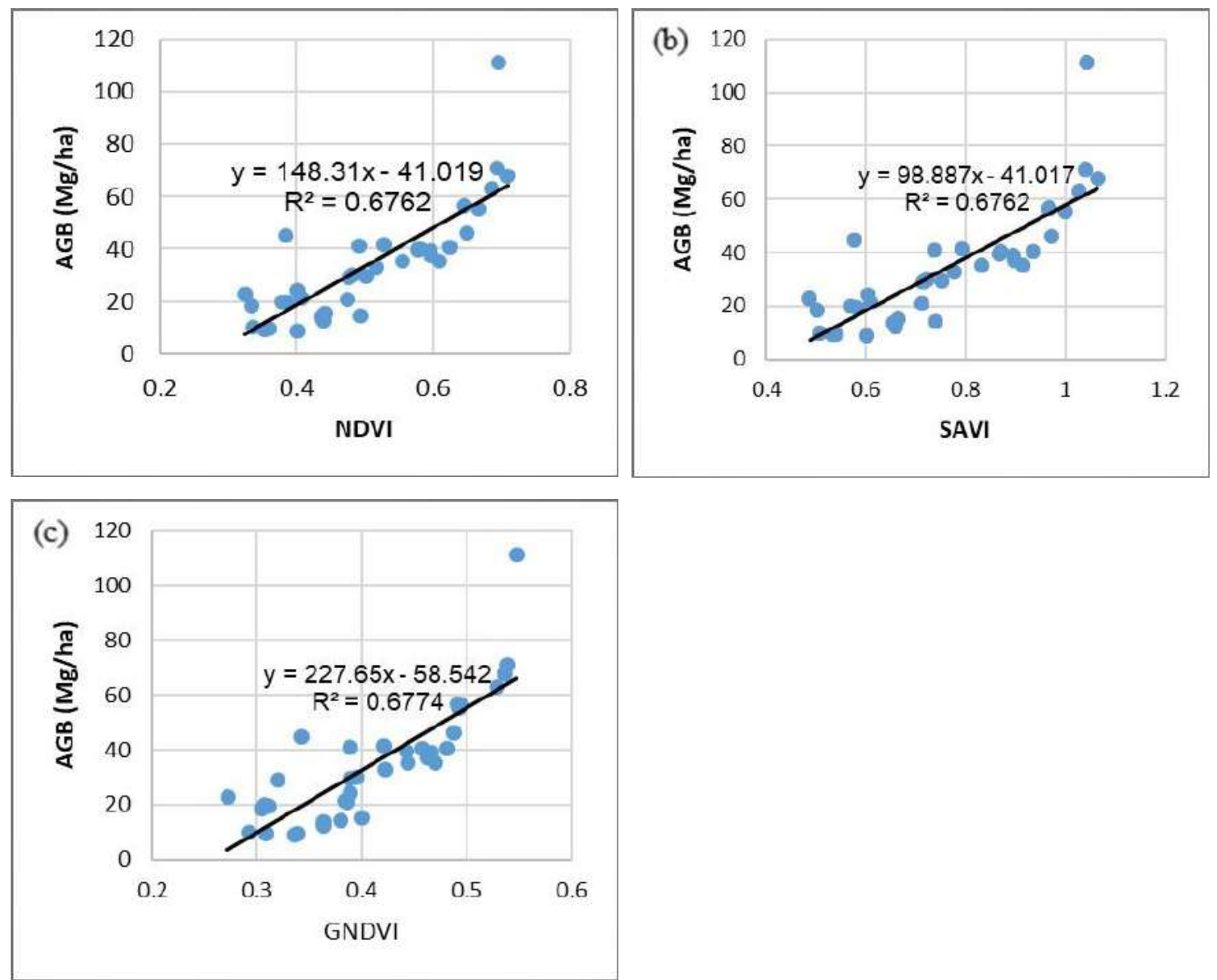

Figure 3. Scatterplots of correlations between aboveground biomass (AGB) and vegetation indices: (a) NDVI = normalized difference vegetation indices, (b) SAVI = soil-adjusted vegetation indices and (c) GNDVI = green NDVI

When understory trees were covered by the canopy layer (Figure 4), the resulting uncounted biomass would lead to an underestimation of total AGB. In this study, most of surveyed sample plots were even-aged pure species, and only one plot was uneven-aged and mixed species. If the mangrove forests in consideration are uneven-aged or mixed species, the accuracy of this method will be low. 
The approach using optical data is commonly used to derive vegetation indices for mangrove biomass estimation. Studies have indicated that vegetation indices are effective for monitoring the change in mangrove area and biomass (Foody et al., 2001; Hamdan, Khairunnisa, Ammar, Hasmadi, \& Aziz, 2013; Lu et al., 2016; Wicaksono, Danoedoro, Hartono, \& Nehren, 2016). This research resulted in a high correlation between vegetation indices and field AGB. This result was in line with (Hamdan et al., 2013; Li et al., 2007) that generated good correlations between vegetation indices and field biomass. Our result was in contrary to (Wicaksono, Danoedoro, Hartono, Nehren, \& Ribbe, 2011) and (Winarso et al., 2017) that NDVI values and other vegetation indices had low correlation with field biomass.
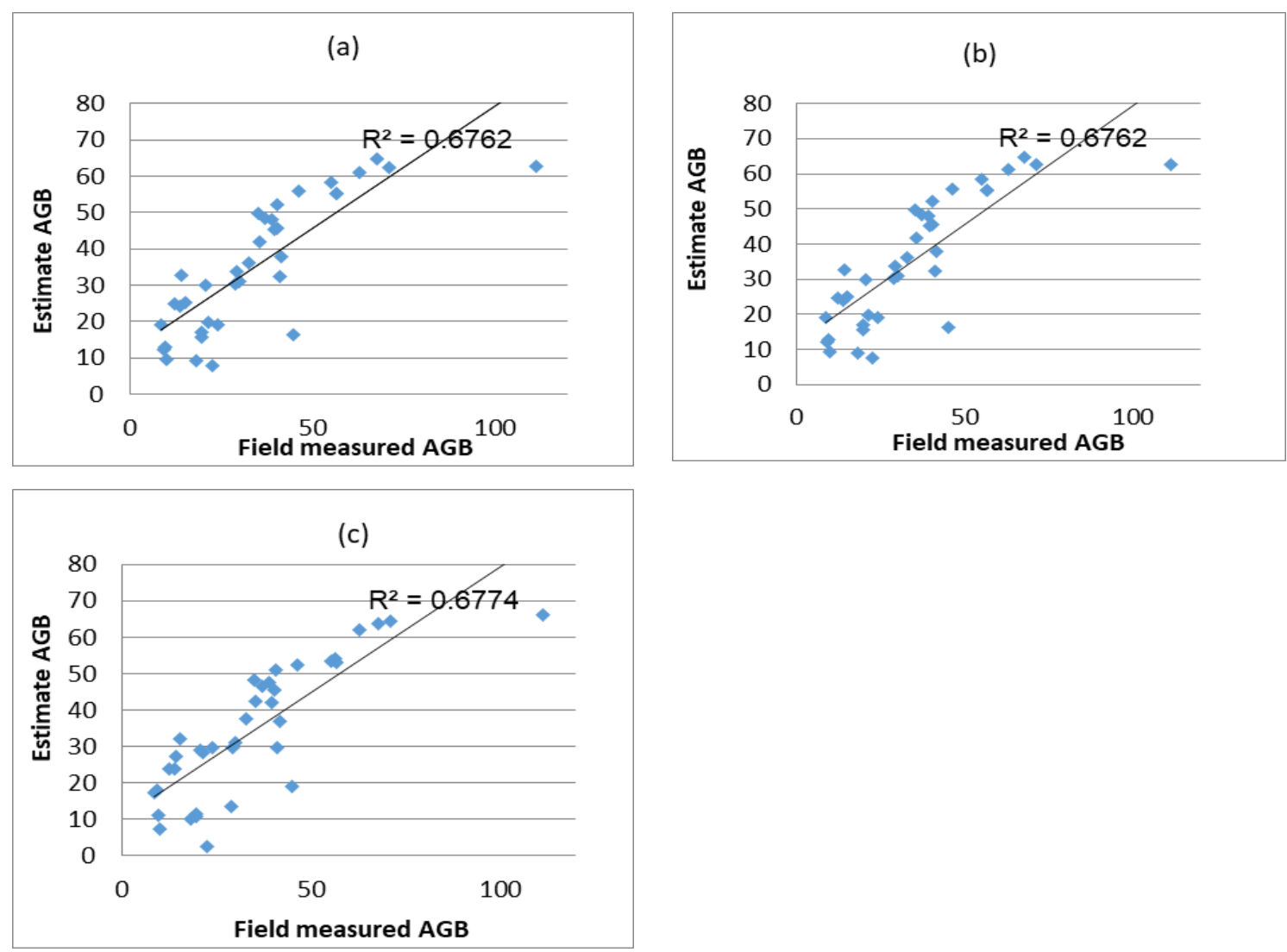

Figure 4. Relationship between measure and estimate $A G B$ in different vegetation indices: (a) $A G B$ estimate by NDVI and field measured AGB, (b) AGB estimate by SAVI and field measured AGB and (c) AGB estimate by GNDVI and field measured AGB

\subsection{Aboveground biomass distribution}

Aboveground biomass mapping was conducted in this study based on the NDVI, SAVI, and GNDVI linear regression model. The AGB was divided into 10 different levels from no biomass to > 80 ton/ha (Figure 5).

After building linear regression models for NDVI, SAVI, and GNDVI in 2018, we used these models for the data of 1998 to estimate the changes in aboveground biomass from 1998 to 2018. The results obtained from AGB in mangroves from 1998 to 2018 are shown in Table 6 . The maximum estimated AGB values by using NDVI linear regression of 1998 and 2018 are 59.1 ton/ha and 78.6 ton/ha. The average AGB in 1998 is 22.57 ton/ha, and in 2018 is 37.74 ton/ha and a standard error of 12.41 ton/ha. 
Table 6. Estimated AGB by NDVI changing from 1998 to 2018

\begin{tabular}{lccc}
\hline \multicolumn{1}{c}{ Parameter } & $\mathbf{1 9 9 8}$ & $\mathbf{2 0 1 8}$ & Total change \\
\hline Total mangrove AGB of the whole study area (ton) & 62880 & 187990 & 125110 \\
Mean area of mangrove AGB (ton/ha) & 22.57 & 37.74 & 15.17 \\
Total area (detect by NDVI) (ha) & 2786 & 4980 & 2194 \\
Maximum AGB (ton/ha) & 59.1 & 78.6 & 19.5 \\
\hline
\end{tabular}

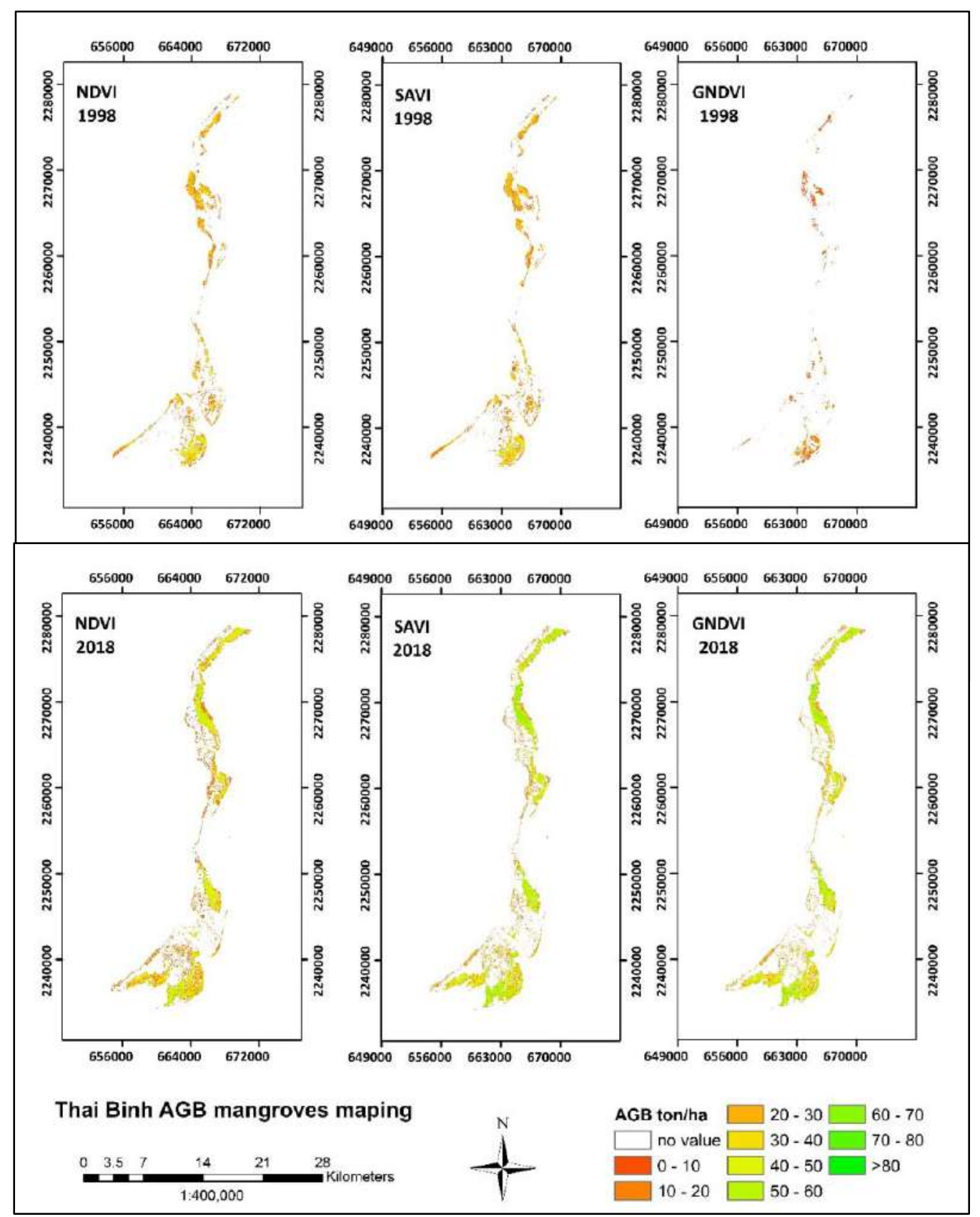

Figure 5. AGB distribution change in different vegetation indices from 1998- 2018 
The study by Darmawan et al. (2015) shows that mangrove AGB in Thai Thuy district, Thai Binh province was 13.87 ton/ha, in Thanh An Can Gio was 31.61 ton/ha, in Giao Thuy district Nam Dinh province was 13.12 ton/ha (Darmawan et al., 2015). Hanh (2017) showed that the average AGB in Dong Hung commune, Tien Lang district, Hai Phong city was 36.80 ton/ha (Hanh, 2017). The result from Dat and Yoshino (2011) showed that mangrove forest area in Thai Binh province increased by 987 ha from 1990 to 2007. If we assume equal yearly increases, this would mean an increase of 58.06 ha per year (Dat \& Yoshino, 2011). This increase in mangrove areas is higher than our study of 22.41 ha per year. Although mangrove areas were increasing in study area, the total mangrove area was decreasing in the Northern coast of Vietnam because considerable decline of mangroves in Quang Ninh and Hai Phong province (Dat \& Yoshino, 2011).

\section{Conclusions}

This study demonstrated that satellite image data could provide useful information for studies on mangroves in Thai Binh province. Our estimation of the extent of mangrove forests in this province showed an increase in the mangrove area in the last 20 years. This increase was generally expected based on the management and protection policies of Thai Binh province, including the ban on clear cutting and forest encroachment. Reforestation/afforestation is also the main reasons for mangrove forest to experience steady increase in coverage area. Diffuse environmental pressures such as decreased freshwater flow, decreased sediment supply, water contamination, and diseases have degraded the forest's condition however, but that degradation is often lower than the relative increase of mangrove forest area.

This study was also able to produce accurate biomass estimation for mangrove trees. Many studies have shown that vegetation indices are highly correlated with vegetation parameters. This study also indicated that vegetation indices might achieve significant accuracy in estimating mangrove biomass in Thai Binh province. A remote sensing model for biomass was produced based on plot data derived from allometric equations using field measurements. The allometric equations were used from Komiyama et al. (2005) and Khan et al. (2005), and we did not apply the destructive method for measuring AGB (Khan et al., 2005; Komiyama et al., 2005). The model was validated using independent validation plots, and the predicted $A G B$ values were within the agreement with the measured AGB data. However, the estimation for two-canopy layer mangrove obtained low accuracy when adopting the model. The satellite data resolution was still limited. Despite these limitations, the remote sensing biomass model developed in this study was able to derive valuable AGB estimation for the coastal mangroves in Thai Binh province.

\section{Acknowledgments}

The authors gratefully thank the Vietnam Administration of Forestry for providing financial support to this study (under the Project of Vietnam Coastal Forest Monitoring, \# 4397/QĐ-BNN-TCLN, 2017-2020). The authors also thank the United States Geological Survey (USGS) for making available Landsat 5, Landsat 7, and Landsat 8 satellite images, which were downloaded from the Global Visualization Viewer for this study.

Conflicts of Interest: The authors declare no conflict of interest

\section{References}

Abburu, S., \& Golla, S. B. (2015). Satellite image classification methods and techniques: A review. International journal of computer applications, 119(8). doi:https://doi.org/10.5120/210883779

Alongi, D. M. (2002). Present state and future of the world's mangrove forests. Environmental conservation, 29(3), 331-349. doi:https://doi.org/10.1017/\$0376892902000231 
Amy E., Z., G., L.-G., David, A. C., Jugo, I., Steven, J., Simon, L. L., . . Jerome, C. (2016). Global Wood Density Database (Publication no. https://doi.org/10.5061/dryad.234/1). https://dryad.figshare.com/articles/Global_Wood_Density_Database/4172847

Anaya, J. A., Chuvieco, E., \& Palacios-Orueta, A. (2009). Aboveground biomass assessment in Colombia: A remote sensing approach. Forest Ecology and Management, 257(4), 1237-1246. doi:https://doi.org/10.1016/j.foreco.2008.11.016

Anderson, G., Hanson, J., \& Haas, R. (1993). Evaluating Landsat Thematic Mapper derived vegetation indices for estimating above-ground biomass on semiarid rangelands. Remote Sensing of Environment, 45(2), 165-175. doi:https://doi.org/10.1016/0034-4257(93)90040-5

Banko, G. (1998). A review of assessing the accuracy of classifications of remotely sensed data and of methods including remote sensing data in forest inventory. IIASA Interim Report(IIASA, Laxenburg, Austria: IR-98-081). doi:http://pure.iiasa.ac.at/5570

Chai, T., \& Draxler, R. R. J. G. m. d. (2014). Root mean square error (RMSE) or mean absolute error (MAE)?-Arguments against avoiding RMSE in the literature. 7(3), 1247-1250.

Cúc, N. T. K. (2013). Nghien cuu kha nang hap thu nang luong song cua rung ngap man trong tai Nam Dinh va Thai Binh.

Darmawan, S., Takeuchi, W., Nakazono, E., Vetrita, Y., Winarso, G., Dien, V. T., . . Sari, D. K. (2015). Characterization of mangrove forest types based on ALOS-PALSAR mosaic for estimating above ground biomass in Southeast Asia. Paper presented at the ACRS 2015-36th Asian Conference on Remote Sensing: Fostering Resilient Growth in Asia, Proceedings.

Dat, P. T., \& Yoshino, K. (2011). Monitoring mangrove forest using multi-temporal satellite data in the Northern Coast of Vietnam. Paper presented at the the 32nd Asian Conf. on Remote Sensing.

FAO. (2007). The world's mangroves 1980-2005. Rome: FAO, FAO Forestry Paper, 153, 77p. doi:http://www.fao.org/3/a1427e/a1427e00.htm

Foody, G. M., Cutler, M. E., Mcmorrow, J., Pelz, D., Tangki, H., Boyd, D. S., \& Douglas, I. (2001). Mapping the biomass of Bornean tropical rain forest from remotely sensed data. Global Ecology and Biogeography, 10(4), 379-387. doi: https://doi.org/10.1046/j.1466822X.2001.00248.x

Giri, C., Ochieng, E., Tieszen, L. L., Zhu, Z., Singh, A., Loveland, T., . . Duke, N. (2011). Status and distribution of mangrove forests of the world using earth observation satellite data. Global Ecology and Biogeography, 20(1), 154-159. doi: https://doi.org/10.1111/j.14668238.2010.00584.x

Giri, C., Pengra, B., Zhu, Z., Singh, A., \& Tieszen, L. L. (2007). Monitoring mangrove forest dynamics of the Sundarbans in Bangladesh and India using multi-temporal satellite data from 1973 to 2000. Estuarine, coastal and shelf science, 73(1-2), 91-100. doi:https://doi.org/10.1016/j.ecss.2006.12.019

Gitelson, A. A., Kaufman, Y. J., \& Merzlyak, M. N. (1996). Use of a green channel in remote sensing of global vegetation from EOS-MODIS. Remote Sensing of Environment, 58(3), 289-298. doi:https://doi.org/10.1016/S0034-4257(96)00072-7

Green, E. P., Clark, C. D., Mumby, P. J., Edwards, A. J., \& Ellis, A. (1998). Remote sensing techniques for mangrove mapping. International journal of remote sensing, 19(5), 935-956. doi:https://doi.org/10.1080/014311698215801

Hamdan, O., Aziz, H. K., \& Hasmadi, I. M. (2014). L-band ALOS PALSAR for biomass estimation of Matang Mangroves, Malaysia. Remote Sensing of Environment, 155, 69-78. doi:https://doi.org/10.1016/j.rse.2014.04.029

Hamdan, O., Khairunnisa, M., Ammar, A., Hasmadi, I. M., \& Aziz, H. K. (2013). Mangrove carbon stock assessment by optical satellite imagery. Journal of Tropical Forest Science, 554-565. 
Hanh, N. T. H. (2017). Studying and Evaluating the Ability to form Carbon Sinks in Biomass of the Pure Sonneratia caseolaris Plantation in the Coastal Area of Tien Lang district, Hai Phong city. 33(1).

Heumann, B. W. (2011). Satellite remote sensing of mangrove forests: Recent advances and future opportunities. Progress in Physical Geography, 35(1), 87-108. doi:https://doi.org/10.1177\%2F0309133310385371

Huete, A. R. (1988). A soil-adjusted vegetation index (SAVI). Remote Sensing of Environment, 25(3), 295-309. doi:https://doi.org/10.1016/0034-4257(88)90106-X

Kamal, M., \& Phinn, S. (2011). Hyperspectral data for mangrove species mapping: A comparison of pixel-based and object-based approach. Remote Sensing, 3(10), 2222-2242. doi:https://doi.org/10.3390/rs3102222

Khan, M. N. I., Suwa, R., \& Hagihara, A. (2005). Allometric relationships for estimating the aboveground phytomass and leaf area of mangrove Kandelia candel (L.) Druce trees in the Manko Wetland, Okinawa Island, Japan. Trees, 19(3), 266-272.

Komiyama, A., Poungparn, S., \& Kato, S. (2005). Common allometric equations for estimating the tree weight of mangroves. Journal of Tropical Ecology, 21(4), 471-477. doi:https://doi.org/10.1017/S0266467405002476

Kumar, L., \& Mutanga, O. (2017). Remote sensing of above-ground biomass. In: Multidisciplinary Digital Publishing Institute.

Landis, J. R., \& Koch, G. G. J. b. (1977). The measurement of observer agreement for categorical data. 159-174. doi:https://doi.org/10.2307/2529310

Li, X., Gar-On Yeh, A., Wang, S., Liu, K., Liu, X., Qian, J., \& Chen, X. (2007). Regression and analytical models for estimating mangrove wetland biomass in South China using Radarsat images. International journal of remote sensing, 28(24), 5567-5582. doi:https://doi.org/10.1080/01431160701227638

Lu, D., Chen, Q., Wang, G., Liu, L., Li, G., \& Moran, E. (2016). A survey of remote sensing-based aboveground biomass estimation methods in forest ecosystems. International Journal of Digital Earth, 9(1), 63-105. doi:https://doi.org/10.1080/17538947.2014.990526

Muhd-Ekhzarizal, M., Mohd-Hasmadi, I., Hamdan, O., Mohamad-Roslan, M., \& Noor-Shaila, S. (2018). Estimation of aboveground biomass in mangrove forests using vegetation indices from SPOT-5 Image. Journal of Tropical Forest Science, 30(2), 224-233. doi:https://doi.org/10.26525/jtfs2018.30.2.224233

Mutanga, O., Adam, E., \& Cho, M. A. (2012). High density biomass estimation for wetland vegetation using WorldView-2 imagery and random forest regression algorithm. International Journal of Applied Earth Observation and Geoinformation, 18, 399-406. doi:https://doi.org/10.1016/j.jag.2012.03.012

Polidoro, B. A., Carpenter, K. E., Collins, L., Duke, N. C., Ellison, A. M., Ellison, J. C., . . Koedam, N. E. (2010). The loss of species: mangrove extinction risk and geographic areas of global concern. PloS one, 5(4), e10095. doi:https://doi.org/10.1371/journal.pone.0010095

Regression, G. W. (2016). Help| ArcGIS for Desktop [Internet]. Desktop. arcgis. com. 2016 [cited 9 March 2016]. In.

Syed, M. A., Hussin, Y. A., \& Weir, M. (2001). Detecting fragmented mangroves in the Sundarbans, Bangladesh using optical and radar satellite images. Paper presented at the Paper presented at the 22nd Asian Conference on Remote Sensing.

Trần, V. T., Phan, T. T., Đoàn, H. G., Phạm, M. D., Nguyễn, T. H., \& Nguyễn, M. Q. (2016). Nghien cuu anh huong cua bien doi khi hau den mot so he sinh thai ven bien tinh Thai Binh va kha nang ung pho. Vietnam National University, 392 - 399.

Tuan, L., Yukihiro, M., Dao, Q., Tho, N., \& Dao, P. (2003). Environmental management in mangrove areas. Environmental Informatics Archives, 1, 38-52. 
Wicaksono, P., Danoedoro, P., Hartono, \& Nehren, U. (2016). Mangrove biomass carbon stock mapping of the Karimunjawa Islands using multispectral remote sensing. International journal of remote sensing, 37(1), 26-52. doi:https://doi.org/10.1080/01431161.2015.1117679

Wicaksono, P., Danoedoro, P., Hartono, H., Nehren, U., \& Ribbe, L. (2011). Preliminary work of mangrove ecosystem carbon stock mapping in small island using remote sensing: above and below ground carbon stock mapping on medium resolution satellite image. Paper presented at the Remote Sensing for Agriculture, Ecosystems, and Hydrology XIII.

Winarso, G., Vetrita, Y., Purwanto, A. D., Anggraini, N., Darmawan, S., \& Yuwono, D. M. (2017). Mangrove above ground biomass estimation using combination of Landsat 8 and Alos Palsar data. International Journal of Remote Sensing and Earth Sciences (IJReSES), 12(2), 85-96. doi:https://doi.org/10.30536/j.ijreses.2015.v12.a2687

Zaitunah, A., Ahmad, A., \& Safitri, R. (2018). Normalized difference vegetation index (ndvi) analysis for land cover types using landsat 8 oli in besitang watershed, Indonesia. Paper presented at the IOP Conference Series: Earth and Environmental Science.

Zheng, D., Rademacher, J., Chen, J., Crow, T., Bresee, M., Le Moine, J., \& Ryu, S.-R. (2004). Estimating aboveground biomass using Landsat 7 ETM+ data across a managed landscape in northern Wisconsin, USA. Remote Sensing of Environment, 93(3), 402-411. doi:https://doi.org/10.1016/j.rse.2004.08.008 